\title{
Justification of modernization of groundwater treatment station
}

\author{
Zhanna Govorova ${ }^{1, *}$, Olga Zubareva ${ }^{2}$, Vasiliy Semenovykh ${ }^{1}$, Ekaterina Muraveva $^{1}$ and \\ Olga Yankovskaya ${ }^{1}$ \\ ${ }^{1}$ Moscow State University of Civil Engineering, Yaroslavskoe shosse, 26, Moscow, 129337, Russia \\ ${ }^{2}$ Moscow State University of Geodesy and Cartography, 4, Gorokhovsky pereulok, 105064, Moscow, \\ Russia
}

\begin{abstract}
The main contaminants of groundwater are iron and manganese compounds, increased hardness, which are removed at groundwater conditioning stations. The article reviews the existing station that was built according to a conventional design and uses the method of simplified aeration with the following filtration through high-silica sand. Assessment of the technical condition of the station showed that the elements of the building are limited to work The filters are in poor condition, some of the filters are out of service, there are concrete corrosion, destruction of finishing layers in filters' building, internal and external corrosion of metallic pipelines and valves, which depend on he quality of transported water. Wear of the technological pipelines is over $80 \%$. Analysis of the efficiency of the station showed that it operates at $50 \%$ capacity and at the same time does not provide standards for the hardness of drinking water. Water consumption for the station's own needs is 1.5 times higher than it was designed. There are no processing and reusing facilities for flushing water. Results of the technical and technological inspection of the station showed that there is a need for immediate modernization of the station including the improvement of the groundwater purification technology and bringing he quality to the standards for drinking water.
\end{abstract}

\section{Introduction}

Artesian water is the main source of water supply for cities and towns of Moscow region of Russian Federation. It provides approximately $87 \%$ of the total domestic water supply. About $80 \%$ of groundwater intake is carried out on residential and industrial area. Groundwater is taken from various aquifers: Kasimovsky, Podolsko-Myachkovsky, etc.

The quality of groundwater aquifers is diverse in physical and chemical composition and depends on the lithological composition of water-bearing materials and the mode of occurrence of the aquifer. The main contaminants of such waters are iron and manganese compounds, increased hardness, the presence of dissolved gases, etc. [1-3].

Groundwater treatment for drinking purposes is carried out at groundwater conditioning

* Corresponding author: fonsvit@bk.ru 
stations. Chemical and nonchemical methods are used depending on the quality of source water [4-13]. In recent years biological deferrization has been used more frequently [2, 1415]. One of the common nonchemical methods of groundwater purification from iron compounds is the filtration through inert load with simplified water aeration by pouring it into the filter's distributing chamber. Compact water purification plants with air-water ejector on the supply pipeline could also be used depending on the capacity of the station [16].

Most of the underground water treatment plants were built in the middle of the last century. Nowadays, most of the stations have outdated water purification technology, purified water does not meet standards, and there are no facilities for the treatment and reuse of flush water. Depreciation of technological pipelines is over $80 \%$, treatment facilities and buildings of the stations are in critical condition and require major repairs.

To solve the urgent problem of providing consumers with drinking water and improving its quality, Russian Federation has initiated the Federal Program "Clean Water". It includes the construction of new stations, as well as the modernization or reconstruction of existing underground water conditioning stations.

Justification of technological and technical solutions for the modernization of the station requires a detailed study of the quality of groundwater, analysis of the treatment technology and composition of water treatment facilities, assessment of the efficiency of existing structures, inspection of the station building and determination of the technical condition of structures of facilities, pipelines and valves. In addition, it is important to conduct field studies of an improved deferrization technology in order to obtain initial data for the development of a modernization or reconstruction project. In addition, it is important to conduct field studies of an improved deferrization technology in order to obtain source data for the development of a modernization or reconstruction project $[3,17]$.

\section{Methods}

The object of the research is the operating deferrization station. The station is located in the Moscow region, it was built according to a conventional design and has been operating since the middle of the last century.

According to conventional design, water deferrization is accomplished by filtration and water enrichment with oxygen right before the filters. Source water from the wells is supplied by pumps of the first lift to filters with an outflow into the central channel at a height of 0.6 $\mathrm{m}$ above the water level. Water is enriched with the required amount of air oxygen due to the height of the fall. After passing through the filter load, the water is purified from iron, disinfected by UV lamps and delivered to clean water reservoirs, from which water is taken by pumps of the second lift and supplied to the consumer.

Filters at the station are open design, made of prefabricated concrete units, rectangular in plan with central water supply channel, $6.0 \times 3.2 \mathrm{~m}$ in grid dimensions. Effective filtration area is $13.8 \mathrm{~m}^{2}$. There are 8 filters on the station. Average filtration rate is $5.0 \mathrm{~m} / \mathrm{h}$, during the flushing of one filter $-5.72 \mathrm{~m} / \mathrm{h}$. High-silica sand is used as a filter media with grain size of $0.8-1.8 \mathrm{~mm}$, height of the load is $1.2 \mathrm{~m}$. Gravel aggregate with the grain size of 2.0-32.0 $\mathrm{mm}$ was used as a supporting layer with the height of $0.5 \mathrm{~m}$. The filters are flushed with purified water which is supplied by flushing pumps from clean water reservoir. The estimated flushing rate is $14-15 \mathrm{l} / \mathrm{s}$ per $\mathrm{m}^{2}$ of filter area. Flushing of one filter for 6 minutes requires $79.5 \mathrm{~m}^{3}$ of purified water. The distribution of water for flushing and the collecting of the filtrate is carried out by drainage system of high resistance which is made of steel perforated pipes with a diameter of $100 \mathrm{~mm}$. Collection and removal of flush water is carried out by troughs with a semicircular bottom.

The quality indicators of groundwater and purified water at the station were determined according to standard methods and using certified equipment of the treatment station's 
laboratory. While conducting an express water quality analysis colorimetric kits and comparators were used to determine the presence of ferrous iron HACH 1467-01 and manganese HACH 1467-00. Measurements of structural elements were made using a DISTO A3 laser rangefinder (Leica), as well as metal measuring tapes and tape measures. Technical inspection of the building structures was carried out using certified and calibrated devices and instruments.

\section{Results}

The water is supplied to the deferrization station from a group of wells. Wells' capacity varies from 70 to $208 \mathrm{~m}^{3} / \mathrm{h}$. Physical and chemical composition of groundwater of wells (2020) is presented in Table 1.

Table 1. Physical and chemical composition of groundwater and drinking water.

\begin{tabular}{|c|c|c|c|c|c|}
\hline Parameter & Well 1 & Well 3 & Well 4 & $\begin{array}{c}\text { Drinking } \\
\text { water }\end{array}$ & $\begin{array}{c}\text { SanPiN } \\
\mathbf{1 . 3 6 8 5 - 2 1}\end{array}$ \\
\hline Odor (point) & 2 & 2 & $1-2$ & 0 & 2 \\
\hline Turbidity (FTU) & $2.1-8.4$ & $0.36-1.52$ & $0.18-2.15$ & $0.1-0.5$ & 2.6 \\
\hline $\begin{array}{c}\text { Chromaticity } \\
\text { (degrees) }\end{array}$ & $18.2-21$ & $5.7-10.2$ & $3.9-14.3$ & $1.8-4.5$ & 20 \\
\hline $\mathrm{pH}$ & $7.42-7.65$ & $7.46-7.61$ & $7.38-7.71$ & $7.46-7.67$ & $6-9$ \\
\hline Total Fe (mg/L) & $6.4-9.2$ & $5.8-7.1$ & $3.51-4.22$ & $0.06-0.1$ & 0.3 \\
\hline Mn (mg/L) & $0.29-0.31$ & $0.22-0.27$ & $0.12-0.14$ & $0.03-0.04$ & 0.1 \\
\hline Ammonium (mg/L) & $0.4-0.74$ & $0.6-0.98$ & $0.62-1.04$ & $0.05-0.1$ & 2.6 \\
\hline Hardness (mmol/L) & $11.8-11.9$ & $10.9-11.2$ & $8.7-10.1$ & $8.8-11$ & 7.0 \\
\hline
\end{tabular}

Analysis of water quality showed that it is characterized by $\mathrm{pH} 7.16-7.77$, increased turbidity (up to 8.4 FTU) and chromaticity (up to 24 degrees), total iron (up to $9.2 \mathrm{mg} / \mathrm{L}$ ) and manganese (up to $0.31 \mathrm{mg} / \mathrm{L}$ ). Groundwater has a high hardness in the range of 8.7-11.9 $\mathrm{mmol} / \mathrm{L}$, which significantly exceeds the standard [18]. The water is characterized by a hydrogen sulfide odor with an intensity of 2 points.

Well operation schedule depends on water consumption which is extremely uneven both during the day and during the month. Fig. 1 shows the example of fluctuation of the average hourly consumption of water entering the station in winter (January) and summer (June) periods of 2020 . The deferrization station operates at $50 \%$ capacity. 


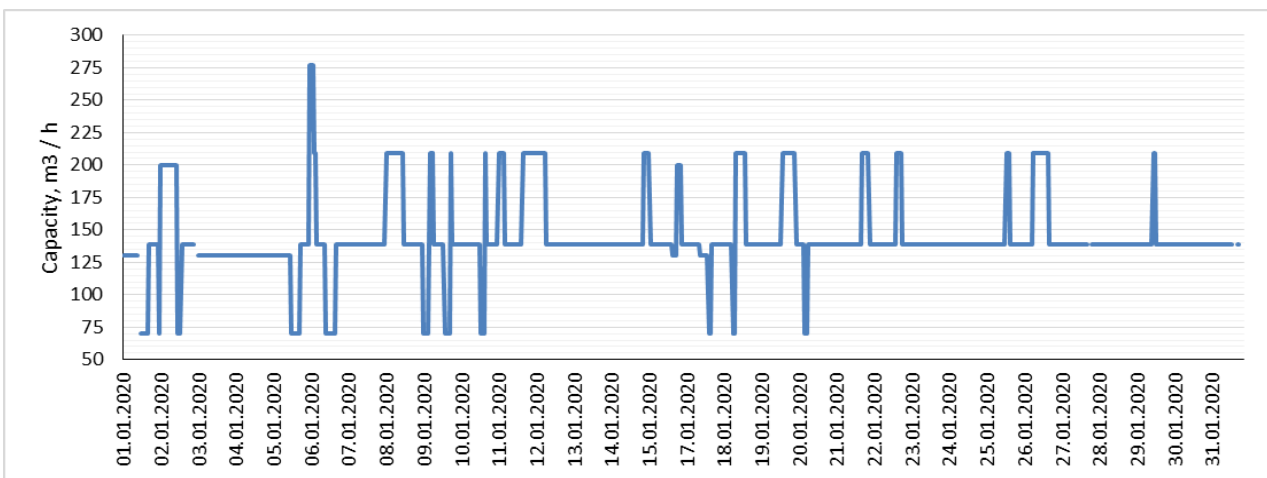

a

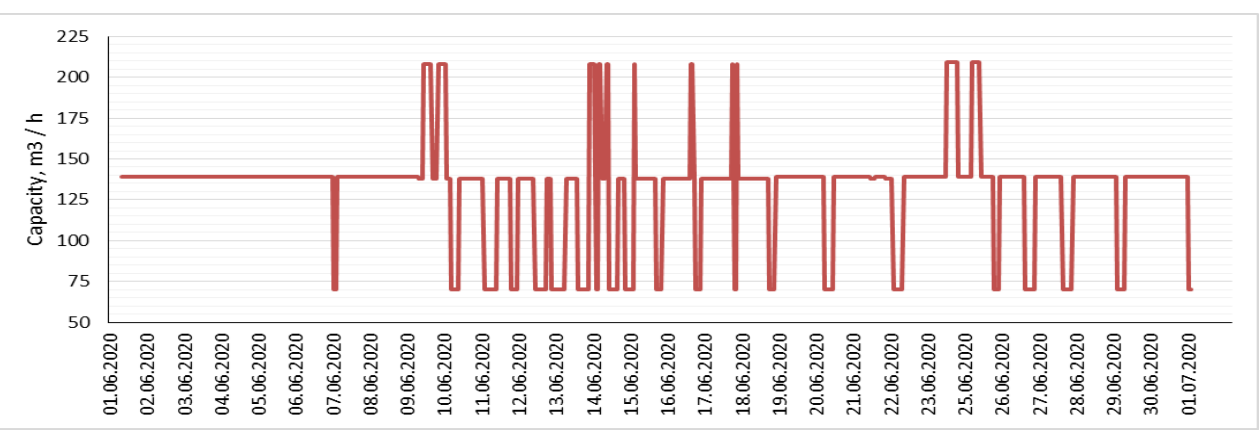

b

Fig. 1. Changes in consumption of water entering the station: a) - January; b) - June.

When the wells' pumps were turned on and off during the day, sharp jumps in flow rates led to a change in the filtration rate (from 1.06 to $3.17 \mathrm{~m} / \mathrm{h}$ ) and, as a result, to periodic washout of sediment from the filter load. This changes negatively affected both the efficiency of the filters and the frequency of their flushing, the duration of the flushing pumps and the water consumption for the station's own needs. Thus, the water consumption for the station's own needs was 9.2 and $6.7 \%$ in January and June respectively, which is significantly higher than the design value (Fig.2).

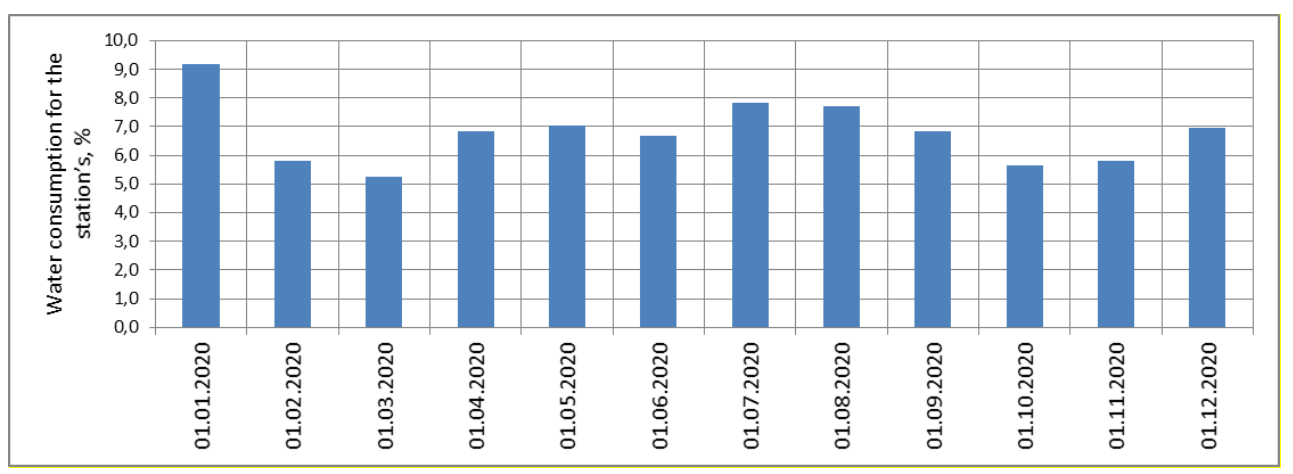

Fig. 2. The water consumption for the station's own needs.

Considering the fact that the deferrization station operates at $50 \%$ capacity, the drinking water quality met the standards for almost all of the monitored parameters [18]. Water hardness was the only exception. Its value in drinking water in 2020 varied from 8.8 to 11 
$\mathrm{mmol} / \mathrm{L}$ (Table 1). The technology adopted by the conventional design did not include water softening because in the $60 \mathrm{~s}$, when the conventional design was developed, groundwater hardness was not higher than $5.4 \mathrm{mmol} / \mathrm{L}$. Over the past 40 years there has been a significant transformation of physico-chemical composition of Podolsko-Myachkovsky aquifer's water.

The technical inspection of the station showed that the condition of the outer walls and roof of the building is limited to work. There is a soaking of the outer walls due to the absence of horizontal and vertical waterproof finish, violation of the finishing layers on the inside of the outer walls due to insufficient thermal covering and high humidity inside the room. The panels of the outer walls do not have the necessary resistance to heat transfer, so, inside the room drizzle settles on the walls, ice forms under the windows.

The general technical condition of the filter housings is unsatisfactory. The finishing layers of the inner surface of filters' room are destroyed, destruction of the concrete walls and decrease in its strength as a result of corrosion are observed, corrosion of the reinforcement is possible as a result of water filtration through the walls. At the time of the inspection three filters were taken out of service.

Fig. 3 and Fig. 4 show parts of the station's buildings, facilities and technological pipelines.
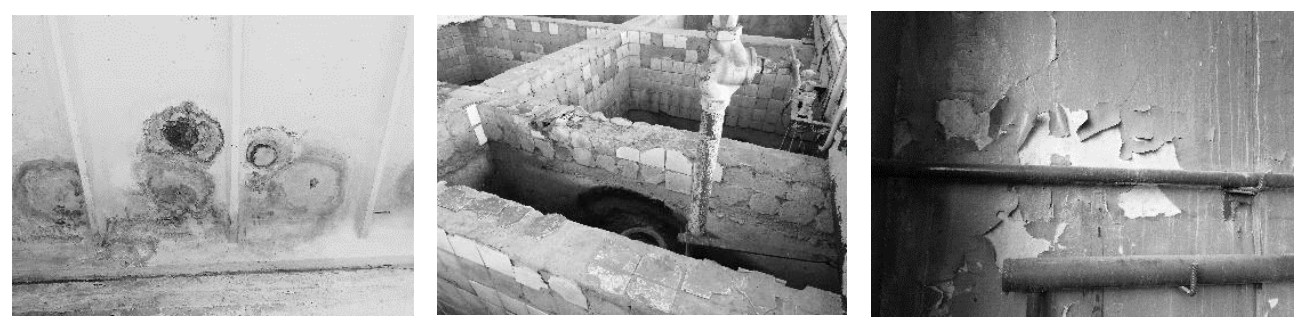

Fig. 3.Technical condition of station's buildings and facilities.
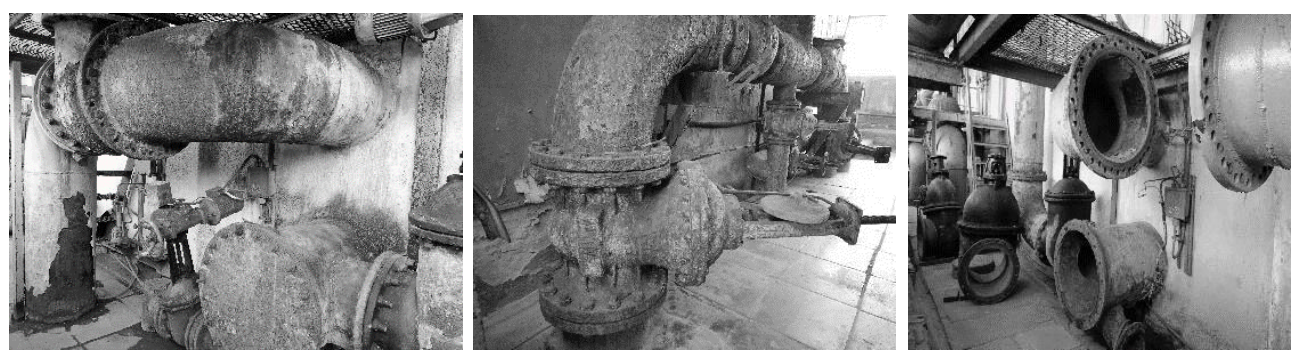

Fig. 4. General appearance of pipelines and valves.

Technological pipelines and valves are exposed to external and internal corrosion. Internal corrosion of pipes depends on the composition of the transported water and is due to its corrosive properties. [19, 20]. There are criteria to assess the stability of water-Langelier Index (LSI), Ryznar Index (RSI), Snoeyink-Jenkins Index, etc .[21]. The first two are most commonly used. The consequences of the deferrization station's pipelines corrosion are encrustation of pipes with corrosion products, increase of roughness and their wear out, as well as a periodic deterioration in the quality of the treated water.

By means of calculation it was found that groundwater of wells №1, 3 and 4 is aggressive and low-corrosive. The maximum value of Langelier Index $I_{L}$ is $(-0.36)$, Ryznar Index $I_{L}-$ (7.94). 


\section{Conclusions}

Analysis of the efficiency of the station showed that the implemented technology provides a decrease in the concentration of iron in treated water from 9.2 to $0.06 \mathrm{mg} / \mathrm{L}$, manganese from 0.31 to $0.03 \mathrm{mg} / \mathrm{L}$. Drinking water hardness exceeds the standard by $1.2-1.5$ times.

The mentioned water quality is achieved at the $50 \%$ of the station's capacity, when three filters are out of service and significant water consumption for the station's own needs is up to $9.2 \%$.

It was concluded that station's buildings and facilities are in a satisfactory condition, the wear of pipelines and valves is $80 \%$.

Thus, a survey of the operating station showed that technology improvement, general overhaul, replacement of pipelines and overall modernization are required.

\section{References}

1. S.R. Kraynov, V.M. Shvets, Geokhimiya podzemnykh vod khozyaystvenno-pit'yevogo naznacheniya, (Nedra, 1987)

2. G.I. Nikoladze, Uluchsheniye kachestva podzemnykh vod (Stroyizdat, 1987)

3. M.G. Zhurba, L.I. Sokolov, Zh.M. Govorova, Vodosnabzheniye. Proyektirovaniye sistem i sooruzheniy: vol. 3 (Publishing house of the Association of construction universities, 2019)

4. V.V. Bykov, Vodoochistka. Vodopodgotovka. Vodosnabzheniye, 9, 22-31 (2017)

5. A.V. Selyukov, I.S. Baikova, Vodosn. i san. tekhnika, 11, 24-29 (2014)

6. V.V. Bykov, Santekhnika. Vodosnabzheniye i inzhenernyye sistemy, 3, 18-23 (2018)

7. N.A. Tsukanov, T.A. Budykina, E.N. Spitsyn, K.Yu. Budykina, Vodosn. i san. tekhnika, 6, 23-30 (2016)

8. E.V. Seredkina, E.P. Kvachan, E.A. Nezhura, Vodosn. i san. tekhnika, 2, 9-15 (2017)

9. P.A. Klebeko, V.I. Romanovsky, Vodosn. i san. tekhnika, 7, 24-29 (2020)

10. A.V. Selyukov, V.V. Rakhimov, Vodosn. i san. tekhnika, 2, 4-7 (2020)

11. J. Civardi, M. Tompeck, Iron and manganese removal (AWWA, 2015)

12. L.P. Alekseeva, V.L. Draginsky, Vodosn. i san. tekhnika 10, 32-36 (2004)

13. Q. Cheng, L. Nengzi, LJ. Bao, Water Sup.: R. and Techn.-AQUA, 3, 157-65 (2017)

14. P. Mouchet, G.N. Gerasimov, Vodosn. i san. tekhnika, 12, 35-39 (2011)

15. Govorova Zh, Muraveva E, Govorov V. and Semenovykh V. Technology of groundwater biological deferrization (2018) MATEC Web Conf. v. 25103036 Available at: https://doi.org/10.1051/matecconf/201825103036

16. Zh. Govorova, V. Semenovykh and O. Govorov. Innovative unit for water treatment (2020) IOP Conf. Series: Materials Science and Engineering v. 869042030 Available at: https://doi:10.1088/1757-899X/869/4/042030

17. Zh.M. Govorova, M.G. Zhurba, Obosnovaniye vodoochistnykh tekhnologiy i ikh investirovaniya (Scientific publication, 2012)

18. SanPiN 1.2.3685-21 (Sanitary Rules and Regulations) Hygiene standards and requirements to ensure safety and (or) harmful for human environmental factors Available at: http://docs.cntd.ru/document/573500115

19. L.A. Kulsky, P.P. Strokach, Tekhnologiya ochistki prirodnykh vod (High school, 1986) 
20. A.A. Kastalsky, D.M. Mints, Podgotovka vody dlya pit'yevogo i promyshlennogo vodosnabzheniya (Higher school, 1962)

21. L.S. Alekseev, Kontrol' kachestva vody (INFRA-M, 2004) 